\title{
In vitro evaluation of Eugenia dysenterica in primary culture of human gingival fibroblast cells
}

Cláudio Rodrigues Rezende COSTA ${ }^{(a)}$ Bruna Rabelo AMORIM(a)

Sandra Márcia Mazutti da SILVA ${ }^{(b)}$

Ana Carolina ACEVEDO(a) (D) Pérola de Oliveira MAGALHÃES(b)

Eliete Neves Silva GUERRA(a)

(a) Universidade de Brasília - UNB, Faculty of Health Sciences, Laboratory of Oral Histopathology, Brasília, DF, Brazil.

(b) Universidade de Brasília - UNB, Faculty of Health Sciences, Laboratory of Natural Products, Brasília, DF, Brazil.

Declaration of Interests: The authors certify that they have no commercial or associative interest that represents a conflict of interest in connection with the manuscript.

Corresponding Author:

Eliete Neves Silva Guerra

E-mail: elieteneves.unb@gmail.com

hitps://doi.org/10.1590/1807-3107bor-2019.vol33.0035

Submitted: August 1, 2018

Accepted for publication: February 16, 2019

Last revision: March 19, 2019
Abstract: Eugenia dysenterica is a Brazilian tree investigated for its properties and bioactive compounds, which are believed to have both pharmacological and phytochemical therapeutic effects. The leaves of this tree contain tannins, flavonoids, terpenes, and saponins, with reportedly beneficial effects to the human body. Despite these therapeutic applications, its effects have never been tested on oral tissues. Therefore, the aim of the present study was to evaluate the cytotoxic and antioxidant effects and the anti-inflammatory and repair properties of the acetone fraction of $E$. dysenterica on primary culture of human gingival fibroblasts and on the immortalized murine macrophage cell line (RAW 264.7). For this purpose, a metabolic activity assay, a wound healing assay, a nitric oxide assay, and RT-qPCR were performed. The assays revealed a cytoprotective effect of this plant, suggested by the increase in the expression of SOD1 and NRF2. An antioxidant potential effect was observed in the DPPH• assay. However, the fraction of E. dysenterica did not show anti-inflammatory activity. In conclusion, Eugenia dysenterica may promote cytoprotection when associated with chlorhexidine digluconate because of its antioxidant effect. However, additional studies are necessary on other human dental tissues using other parts of the plant in order to develop a possible mouthwash to assist patients with oral disorders.

Keywords: Eugenia; Fibroblasts; Antioxidants; Chlorhexidine.

\section{Introduction}

Oral mucositis is characterized by atrophy and rupture of epithelial tissue, followed by ulcerations with direct clonogenic cell death as a consequence of oxidative stress arising from chemotherapeutic and radiotherapeutic treatments of patients with head and neck cancer., ${ }^{1,2}$ At the stage of ulceration, the affected patient is prone to infection and is at risk for bacteremia and sepsis. Due to the presence of colonizing bacteria, the activation of macrophages triggers an inflammatory response, releasing cytokines. ${ }^{3}$ Desquamation of the oral mucosa followed by erythema and ulceration causes pain and burning, interfering with speech, swallowing, and oral hygiene. It can also interfere with nutritional status or even limit or lead to the discontinuation of cancer therapy. ${ }^{2}$ In addition, as a result of xerostomia and immunosuppression, there is biofilm formation by gram-negative bacteria and yeasts, such as candidosis. ${ }^{4}$ 
Chlorhexidine digluconate (CHX) at the concentrations of $0.12 \%$ and $0.2 \%$ is currently used in the treatment of dental and oral mucosal disorders. ${ }^{5,6}$ $\mathrm{CHX}$ is a broad-spectrum antibacterial and antifungal agent $^{7}$ against mucositis, used in mouthwashes, which help lubricate the oral cavity and increase cellular safety; ${ }^{8,9}$ however, exacerbated pain and burning sensation have been described after its use. $^{5}$ Therefore, $\mathrm{CHX}$ may be contraindicated for the treatment of mucositis.

Medicinal plants have traditionally been used as an alternative to treat diseases of the oral mucosa, explaining the necessity to investigate the pharmacological potential of their bioactive components. ${ }^{10,11}$ Eugenia dysenterica DC (ED), is a fruit tree native to the Brazilian Cerrado belonging to the family Myrtaceae. In general, its leaves are used as an antidiarrheal, since its fruits have laxative properties, according to popular wisdom. However, in the literature, little has been reported on the chemical and biological activities of this plant. Preliminary analysis has indicated the presence of catechin and epicatechin, the former of which is found at larger concentrations. ${ }^{12}$ Moreover, several studies have reported antifungal,,$^{13}$ antioxidative, ${ }^{14}$ and cytoprotective effects of ED. ${ }^{15}$

Several plants have been used in the treatment of oral mucosal disorders, ${ }^{16}$ but the effects of ED on oral tissues have never been tested. Therefore, the aim of this study is to investigate these effects and to reduce the adverse effects of CHX on oral tissues. To do that, we propose the use of an acetone fraction of ED (AFED) in primary human gingival fibroblast cell (hGFC) culture associated or not with CHX solutions at $0.12 \%$ and $0.2 \%$ concentrations to evaluate their antioxidant properties and the possibility of improvement of mouthwashes currently available on the market.

\section{Methodology}

\section{Treatments: Eugenia dysenterica and chlorhexidine digluconate}

E. dysenterica was obtained from the Cerrado biome, part of the Brazilian savannah. ED was identified by an experienced researcher from the
Institute of Biological Sciences of the University of Brasilia, process UB 914. Pure and aqueous extracts were obtained from the leaves of ED and previously tested for selection of the solution to be used in this study (data not shown). The leaves of ED were collected and dried at room temperature. After the leaves were dried, they were crushed and infused with $200 \mathrm{~g}$ of the material in $1 \mathrm{~L}$ of distilled water at $70^{\circ} \mathrm{C}$ in a closed container. After the infusion reached $40^{\circ} \mathrm{C}$, the resulting solution was filtered and lyophilized. The crude aqueous extract of ED was obtained and subsequently allowed to precipitate after being washed with acetone, which was used as a pure solvent. Thirty milliliters of the solvent was mixed and homogenized into the crude aqueous extract of ED, with subsequent separation of the precipitate and supernatant after decanting. This procedure was repeated three times prior to evaporation and preparation of the acetone fraction of the crude aqueous extract of the plant. The fraction obtained was kept under refrigeration $\left(-30^{\circ} \mathrm{C}\right)$ until used in the tests. The AFED yield was $1.67 \%$. These vegetable derivatives were manufactured at the Laboratory of Natural Products of the University of Brasilia. For CHX treatment, the standard solution of CHX was manipulated in a compounding pharmacy at a concentration of $2 \%$ in distilled water, q.s.: $20 \mathrm{~mL}$.

\section{Cell culture}

All study protocols were approved by the Research Ethics Committee of the Faculty of Health Sciences, University of Brasilia (CAAE: 35371514.5.0000.0030), and complied with the Declaration of Helsinki. Human gingival mucosa was isolated from third molars extracted from five healthy young donors aged 18 to 23 years. The tissues were washed 3 times with phosphate-buffered saline (PBS). The tissues were cut into $1-2 \mathrm{~mm}^{3}$ pieces, placed into 35-mm culture dishes, and incubated with growth medium (Dulbecco's modified Eagle's medium (DMEM) supplemented with $20 \%$ fetal bovine serum (FBS), 10,000 IU/mL of penicillin G sodium, $100,000 \mu \mathrm{g} / \mathrm{mL}$ of streptomycin sulfate, $25 \mu \mathrm{g} / \mathrm{mL}$ of amphotericin $\mathrm{B}$, and $1 \%$ of L-glutamine) at $37^{\circ} \mathrm{C}$, in an atmosphere containing $5 \% \mathrm{CO}_{2}$. The growth medium was replaced every 4 days, and a growth 
medium supplemented with 10\% FBS was used from the first passage. After reaching confluence, the outgrown cells were subcultured using $0.25 \%$ trypsin-EDTA. All experiments were performed using cells from the third to the sixth passages.

RAW 264.7 murine macrophage cells were obtained from the Adolf Lutz Institute's Cell Bank of the American Type Culture Collection (ATCC®, $\mathrm{TIB71}^{\mathrm{TM}}$ ). The cells were maintained in liquid nitrogen (cryopreservation) in a freezing solution containing $5 \%$ dimethyl sulfoxide (DMSO) and 22\% FBS. Raw 264.7 cells were cultured in DMEM supplemented with $10 \%$ FBS and $1 \%$ of penicillin-streptomycin and maintained at $37^{\circ} \mathrm{C}$ in a humidified atmosphere with $5 \% \mathrm{CO}_{2}$.

\section{Metabolic activity assay}

Human gingival fibroblast cells (hGFC) were plated at a density of $1 \times 10^{5}$ cell per well and incubated overnight at $37^{\circ} \mathrm{C}$ and under $5 \% \mathrm{CO}_{2}$ in 96-well plates to facilitate cell attachment and spreading before experimentation. Concentrations of $1.0 \mu \mathrm{g} / \mathrm{mL}, 2.0 \mu \mathrm{g} / \mathrm{mL}, 4.1 \mu \mathrm{g} / \mathrm{mL}, 8.3 \mu \mathrm{g} / \mathrm{mL}$, $20.75 \mu \mathrm{g} / \mathrm{mL}, 41.5 \mu \mathrm{g} / \mathrm{mL}$, and $83.0 \mu \mathrm{g} / \mathrm{mL}$ were previously tested, but they were cytotoxic to hGFC (data not shown). Subsequently, the cells were treated with $0.25 \mu \mathrm{g} / \mathrm{mL}$ and $0.5 \mu \mathrm{g} / \mathrm{mL}$ of AFED extract (data used in this study). Cytotoxicity was compared to the negative control with DMEM at $2 \%$ FBS and also to the use of $\mathrm{CHX}$ at $0.12 \%$ and $0.2 \%$. After $24 \mathrm{~h}$, $10 \mu \mathrm{L}$ of $5 \mathrm{mg} / \mathrm{mL} 3-(4,5-$ dimethyl-thiazol-2-yl)-2,5diphenyltetrazolium bromide (MTT) reagent was added to the culture plates, and cell viability was assessed based on the reduction of the MTT reagent into an insoluble, dark purple formazan product by viable cells. Absorbance was measured using a microplate reader (Thermo Plate TP Reader, Thermo Fisher Scientific, Waltham, MA, USA) at $570 \mathrm{~nm}$. One experiment was performed for each of the groups, and each was measured in octuplicate.

\section{Wound healing assay}

The cells were plated at $1 \times 10^{6}$ cells/well onto fibronectin-coated 6-well plates. The cell monolayer was scratched manually with a yellow plastic pipette tip, washed with PBS, and treated with $0.25 \mu \mathrm{g} / \mathrm{mL}$ and $0.5 \mu \mathrm{g} / \mathrm{mL}$ of AFED leaf extract, with or without $\mathrm{CHX}$ at $0.12 \%$ and $0.2 \%$, and with the control (PBS) in culture medium. An inverted microscope (Zeiss Primo Vert, Göttingen, Germany) equipped with a digital camera (Zeiss ERc 5s, Göttingen, Germany) was used to obtain images of the wound in different periods of treatment at a 10X magnification. Wound closure was monitored for 72 hours, counting from hour zero, until the margins of the wound could no longer be identified. Wound closure was measured by the wound area in each period and expressed as percentage of the initial wound area at hour zero, comparing the extract to the control.

\section{Nitric oxide assay}

The nitric oxide (NO) assay was performed as previously described, with some modifications. ${ }^{17} \mathrm{RAW}$ 264.7 cells $\left(0.3 \times 10^{6}\right.$ cells/well) were seeded into 12-well plates and incubated at $37^{\circ} \mathrm{C}$ for $24 \mathrm{~h}$ in a humidified atmosphere containing $5 \% \mathrm{CO}_{2}$. The attached cells were co-incubated with AFED $(0.25 \mu \mathrm{g} / \mathrm{mL}$ and $0.5 \mu \mathrm{g} / \mathrm{mL}$ ) and $1 \mu \mathrm{g} / \mathrm{mL}$ of Escherichia coli (O55:B5) lipopolysaccharide (LPS) at $37^{\circ} \mathrm{C}$ in a humidified atmosphere containing $5 \% \mathrm{CO}_{2}$ for another 48 hours. Subsequently, $100 \mu \mathrm{L}$ of culture supernatant was mixed with an equal volume of Griess reagent and absorbance was measured at $540 \mathrm{~nm}$. The amount of nitrite in the extract was calculated based on the standard curve generated with sodium nitrite (0-100 $\mu \mathrm{M})$. Each assay was carried out in triplicate and the results were expressed as micromolar concentration of NO production.

\section{DPPH・ assay}

The AFED solution was diluted in 95\% ethyl alcohol at the concentration of $10 \mathrm{mg} / \mathrm{mL}$, and from this solution, dilutions were obtained with the same solvent. $10 \mu \mathrm{L}$ of this sample at different concentrations $(0.38-7.38 \mu \mathrm{g} / \mathrm{mL}$ ) or $10 \mu \mathrm{L}$ of $95 \%$ ethanol (negative control) was diluted in $100 \mu \mathrm{L}$ of $95 \%$ ethanol, $100 \mu \mathrm{L}$ of sodium acetate/acetic acid buffer $(100 \mathrm{mM})$, and $50 \mu \mathrm{L}$ of DPPH• (500 mM) (2.2-diphenyl-1-picrylhydrazine). $150 \mu \mathrm{L}$ of $95 \%$ ethanol and $100 \mu \mathrm{L}$ of buffer plus $10 \mu \mathrm{L}$ of the sample were used for the blank solution. $\mathrm{DPPH} \bullet$ was added at time 0 and the reaction time was measured in 15 minutes. At the end, absorbance 
was read on a spectrophotometer at $517 \mathrm{~nm}$. The IC 50 was determined by the equation of the line obtained for the samples, according to Locatelli et al. ${ }^{18}$

\section{Quantitative reverse transcription PCR (RT-PCR)}

hGFC $\left(2.5 \times 10^{5}\right.$ cells/well) were seeded into 6-well plates, treated with AFED $(0.25 \mu \mathrm{g} / \mathrm{mL}$ and $0.5 \mu \mathrm{g} / \mathrm{mL}$ ), and combined or not with $\mathrm{CHX}$ (0.12\% and 0.2\%). DMEM with $2 \%$ FBS was used in the negative control. After $24 \mathrm{~h}$, total RNA was isolated using TRIzol reagent (Invitrogen) and treated with DNAse I (Sigma Aldrich, St Louis, $\mathrm{MO})$, following the manufacturer's instructions. cDNA was synthesized using $1 \mu \mathrm{g}$ of total RNA and the High Capacity cDNA Reverse Transcription kit (Applied Biosystems, Foster City, CA). Quantitative polymerase chain reaction ( $\mathrm{qPCR}$ ) was performed in triplicate in $10-\mu \mathrm{L}$ reactions by using PowerUp SYBR Green Master Mix (Applied Biosystems StepOnePlus RT-PCR Systems). The following genes were analyzed: interleukin-1 beta (IL1b), interleukin-6 (IL6), nuclear factor erythroid 2-related factor 2 (NRF2), and superoxide dismutase 1 (SOD1). Beta-actin was used as a housekeeping gene, and relative quantification of gene expression was calculated by the comparative cycle threshold $(\mathrm{Ct})$ method. Primer sequences are presented in Table.

\section{Statistical analysis}

All experiments were carried out in triplicate and the data were expressed as mean SD (standard deviation). Student's t-test was applied to assess the presence of significant differences $(p<0.05)$ between the treatments and the control in the MTT assay. All the statistical analyses were performed using GraphPad Prism, version 7.2. For the metabolic activity assay, the statistical analysis was performed by one-way ANOVA with Tukey's test on the means of octuplicate samples. Statistical differences were determined by the non-parametric Mann-Whitney test for the gene expression assay. $p<0.05$ was considered to be statistically significant.

\section{Results}

\section{AFED shows no cytotoxic effects on hGFC}

The cell viability of hGFC was evaluated after treatment with AFED associated or not with CHX solutions. Results show that the two AFED concentrations $(0.25 \mu \mathrm{g} / \mathrm{mL}$ and $0.5 \mu \mathrm{g} / \mathrm{mL})$ had no cytotoxic effect on hGFC, whereas the two CHX concentrations (0.12 and $0.2 \%)$ were extremely cytotoxic. Results also demonstrate the increase in cell viability when different $\mathrm{CHX}$ concentrations were combined with AFED extracts. This is more evident at concentrations of $0.12 \%$ for $\mathrm{CHX}$ and of $0.25 \mu \mathrm{g} / \mathrm{mL}$

Table. Polymerase chain reaction (PCR) primer sequences.

\begin{tabular}{|c|c|c|c|}
\hline Name & Primer & Sequence & Product length \\
\hline \multirow{2}{*}{ Beta-actin } & Forward primer & GTCGAGTCGCGTCCACC & \multirow{2}{*}{86} \\
\hline & Reverse primer & GTCATCCATGGCGAACTGGT & \\
\hline \multirow{2}{*}{ IL $1 b$} & Forward primer & ATGATGGCTTATTACAGTGGCAA & \multirow{2}{*}{132} \\
\hline & Reverse primer & GTCGGAGATTCGTAGCTGGA & \\
\hline \multirow{2}{*}{ IL6 } & Forward primer & CCTGAACCTTCCAAAGATGGC & \multirow{2}{*}{75} \\
\hline & Reverse primer & TTCACCAGGCAAGTCTCCTCA & \\
\hline \multirow{2}{*}{ NRF2 } & Forward primer & TTCCCGGTCACATCGAGAG & \multirow{2}{*}{109} \\
\hline & Reverse primer & TCCTGTTGCATACCGTCTAAATC & \\
\hline \multirow{2}{*}{ SOD1 } & Forward primer & GGTGGGCCAAAGGATGAAGAG & \multirow{2}{*}{227} \\
\hline & Reverse primer & CCACAAGCCAAACGACTTCC & \\
\hline
\end{tabular}

IL1B: Interleukin 1 beta; IL6: Interleukin 6; NRF2: nuclear factor erythroid 2-related factor 2; SOD1: superoxide dismutase 1. 
for AFED. At the concentration of $0.5 \mu \mathrm{g} / \mathrm{mL}$ of AFED, there was an increase in cell viability, both for $\mathrm{CHX}$ $0.2 \%$ and $\mathrm{CHX} 0.12 \%$ (Figure 1). The results were statistically significant $(\mathrm{p}<0.005)$.

\section{AFED does not interfere with wound healing of hGFC}

The effect of AFED on the wound healing of hGFC was assessed. The wound healing assay showed that the AFED extract at the two concentrations did not interfere with the wound closure of hGFC when compared to the control group ( $p<0.0001)$. The concentration of $0.5 \mu \mathrm{g} / \mathrm{mL}$ presented a larger area covered by the cells within the first $12 \mathrm{~h}$, and all groups showed complete closure of monolayer lesions

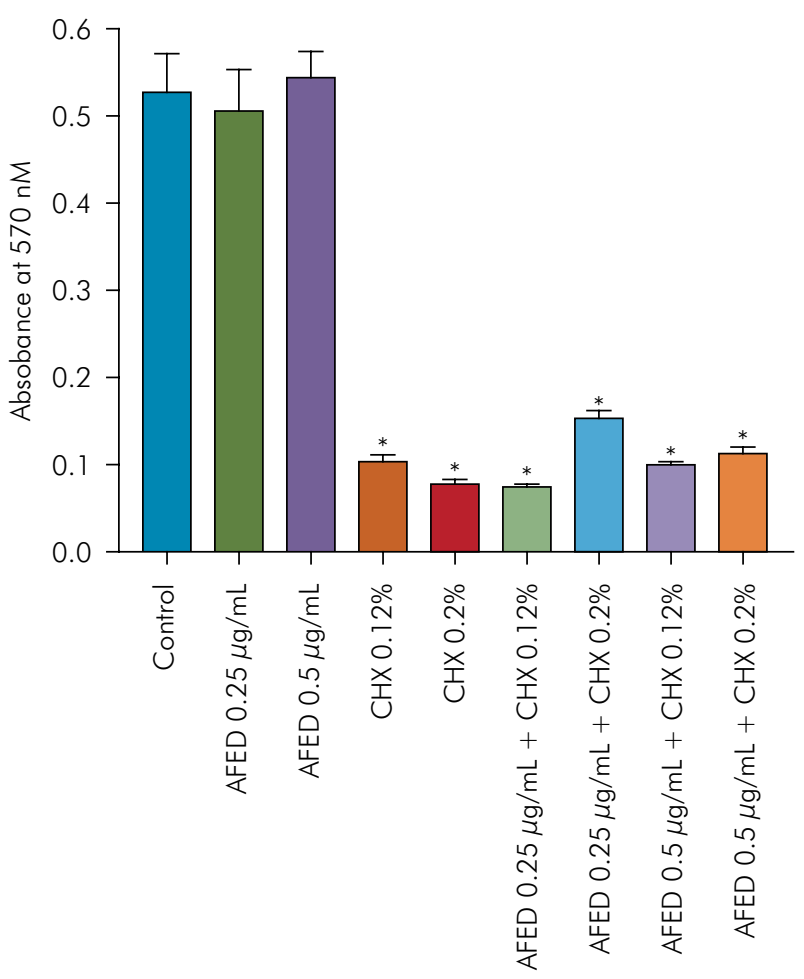

Figure 1. Effect of acetone fraction of Eugenia dysenterica (AFED) on cell viability of gingival fibroblast cells (GFC) under chlorhexidine (CHX) treatment. The MTT assay was performed to measure cell viability of GFC after treatment with AFED $0.25 \mu \mathrm{g} / \mathrm{mL}$ and with AFED $0.5 \mu \mathrm{g} / \mathrm{mL}$; CHX 0.12\%; CHX $0.2 \%$; AFED $0.25 \mu \mathrm{g} / \mathrm{mL}+\mathrm{CHX} 0.12 \%$ or AFED $0.25 \mu \mathrm{g} / \mathrm{mL}$ + CHX 0.2\%; AFED $0.5 \mu \mathrm{g} / \mathrm{mL}+\mathrm{CHX} 0.12 \%$ or AFED $0.5 \mu \mathrm{g} / \mathrm{mL}+\mathrm{CHX} 0.2 \%$. Controls were maintained in regular medium. The statistical analysis (one-way ANOVA with Tukey's test) compares treatment with control $\left({ }^{*} p<0.005\right)$. after $60 \mathrm{~h}$ (Figure 2). CHX concentrations $(0.12 \%$ and $0.2 \%$ ) were assessed, but microphotographs could not be obtained because of some technical difficulties (data not shown).

\section{AFED does not inhibit the production of inflammatory mediators as observed in the nitric oxide assay}

The NO assay with RAW 264.7 cells demonstrated that $0.25 \mu \mathrm{g} / \mathrm{mL}$ and $0.5 \mu \mathrm{g} / \mathrm{mL}$ of AFED inhibited nitric oxide production by $5.5 \%$ and $6.7 \%$, respectively (Figure 3). Given the percentage rates of inhibition of nitric oxide production, it can be stated that the production of this inflammatory mediator was not inhibited at these concentrations. There was no statistical difference between the analyzed groups.

\section{Antioxidant activity by DPPH • radical scavenging}

The DPPH• assay is based on an electron transfer that produces a strong purple solution in ethanol, as evidenced by spectrophotometry. ${ }^{19}$ The concentration necessary for $50 \%$ sequestration of DPPH • radicals compared to the ascorbic acid standard determines the inhibitory concentration (IC 50). AFED presented an antioxidant activity comparable to that of ascorbic acid. The IC 50 values, obtained by linear regression, for AFED and ascorbic acid, presented coefficients of determination of 0.9682 and 0.9811 , respectively. The antioxidant activity of AFED and ascorbic acid showed IC 50 of $3.53 \mu \mathrm{g} / \mathrm{mL}$ and $3.36 \mu \mathrm{g} / \mathrm{mL}$, respectively. The antioxidant activity of AFED was very similar to that of the ascorbic acid standard (Figure 4), but the difference between the groups was not significant.

\section{hGFC can express pro-inflammatory cytokines and antioxidant genes under AFED treatment}

The gene expression assay on pro-inflammatory cytokines showed that hGFC expressed IL1b in the AFED treatment as well as in untreated cells at both concentrations $(0.25 \mu \mathrm{g} / \mathrm{mL}$ and $0.5 \mu \mathrm{g} / \mathrm{mL})$. When cells were treated with $\mathrm{CHX}$, at both concentrations $(0.12 \%$ and $0.2 \%)$, either alone or combined with AFED, IL1b expression was clearly downregulated, 
A

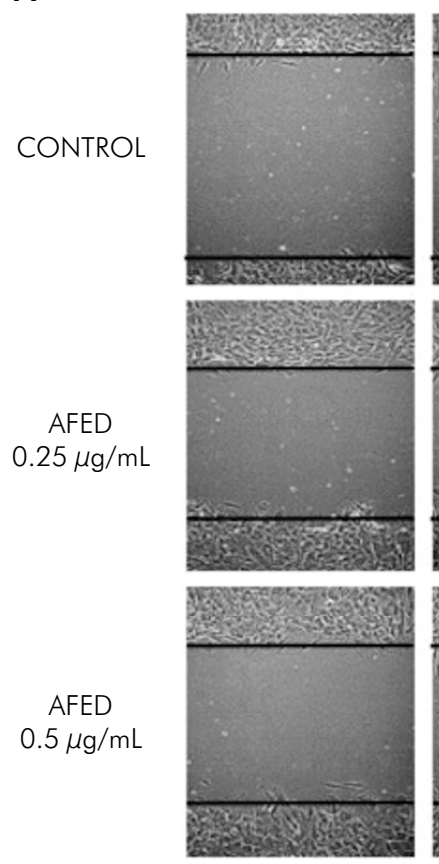

$12 \mathrm{~h}$
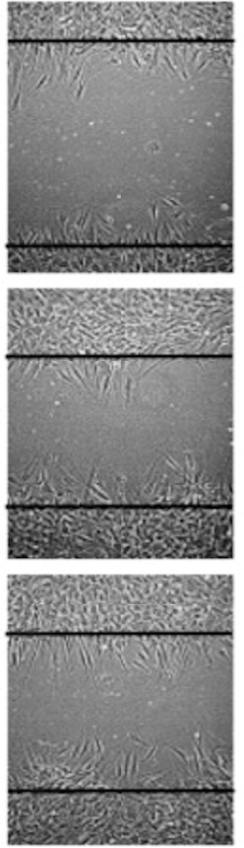

$24 \mathrm{~h}$
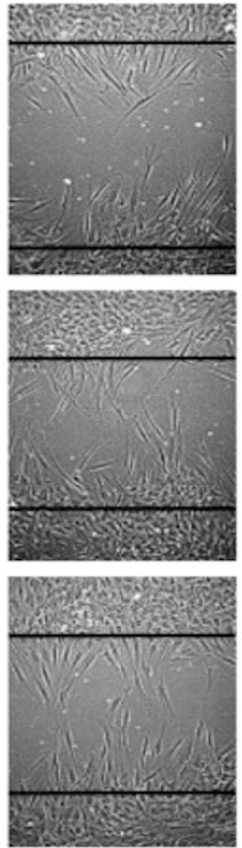

$36 \mathrm{~h}$
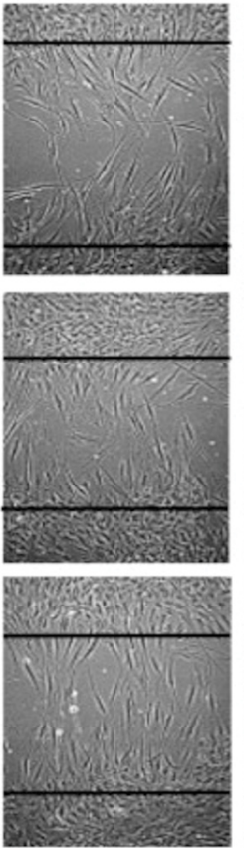

$48 \mathrm{~h}$
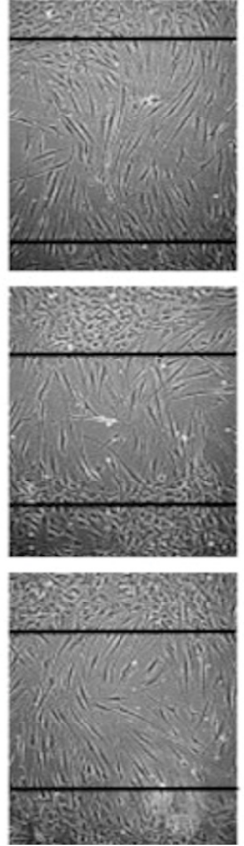

$60 \mathrm{~h}$
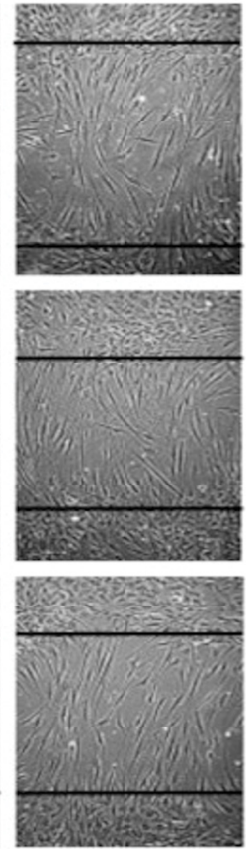

\section{B}
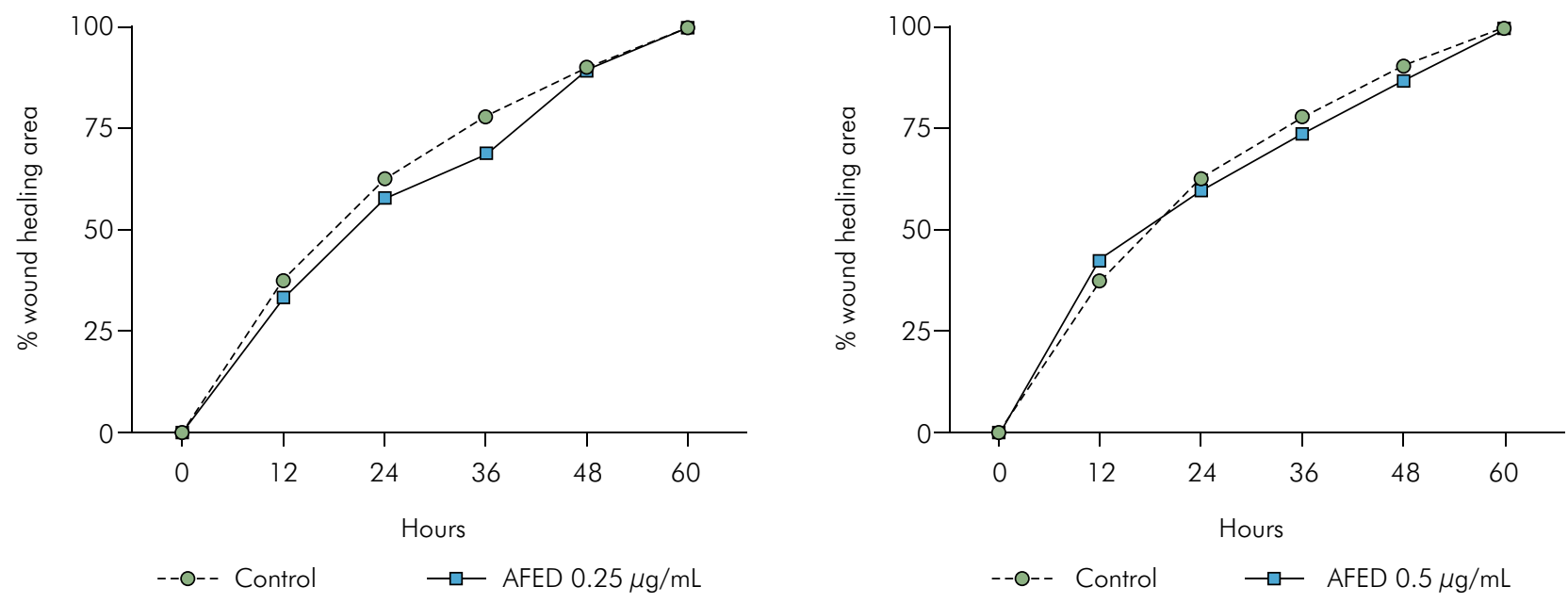

Figure 2. Wound healing assay on gingival fibroblast cells (GFC) treated and not treated with acetone fraction of Eugenia dysenterica (AFED). Cell migration was monitored using a Zeiss Microscope (ERC 5s, Göttingen, Germany) and images were obtained at 0, 12, $24,36,48$, and $60 \mathrm{~h}$ after the wound gap created by "scratching" of the cell monolayer (10x magnification) (A). Wound healing area measured by calculating the wound area in each period, expressed as a percentage of the initial wound area at time zero, with the extract compared to the control (B). The data present $p<0.0001$ versus control.

although the difference between the groups was not significant (Figure 5A). Gene expression changes in antioxidant genes showed that hGFC expressed NRF2 and SOD1 when treated or not with AFED at both concentrations. A minor upregulation in NRF2 (Figure 5C, right side) and SOD1 (Figure 5D, right side) expression was observed in cells treated with CHX $0.2 \%$ and also with CHX $0.2 \%$ combined with AFED $0.5 \mu \mathrm{g} / \mathrm{mL}$, but no significant difference was detected. Probably, the difference was not significant between the groups due to the variability of gene expression among the three cell populations observed. 


\section{Discussion}

Mucositis is an oral disorder in which there is connective tissue exposure induced by cancer therapy,

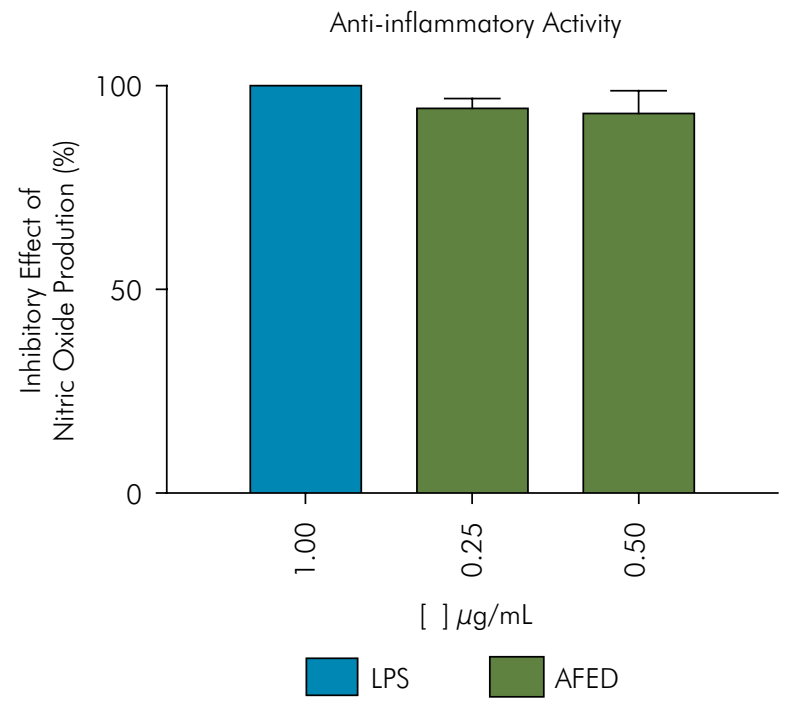

Figure 3. Effect of acetone fraction of Eugenia dysenterica (AFED) on anti-inflammatory activity. RAW 264.7 cells were incubated with AFED $(0.25$ and $0.5 \mu \mathrm{g} / \mathrm{mL})$ and $1 \mu \mathrm{g} / \mathrm{mL}$ of Escherichia coli lipopolysaccharide for $48 \mathrm{~h}$ and the inhibitory effect of nitric oxide production was determined. There was no statistical difference between the groups. and $\mathrm{CHX}$ is one of the treatment options described in the literature. However, it is known that $\mathrm{CHX}$ can exacerbate burning of the mucosa and cause a high level of pain during mouth rinsing. ${ }^{5}$ It is therefore necessary to investigate biopharmaceuticals in an attempt to reduce the adverse effects of $\mathrm{CHX}$ on oral tissues.

In vitro studies reveal a possible cytotoxic effect of $\mathrm{CHX}$ on the plasma membrane, causing its rupture depending on the concentrations used. ${ }^{20} \mathrm{By}$ contrast, mouthwashes containing natural products and plant derivatives have shown a promising capability to prevent diseases caused by biofilm accumulation, presenting antimicrobial activities against several pathogens. ${ }^{16}$

By comparatively evaluating the cytotoxic effects of AFED, our study demonstrated high cytotoxic effect of CHX on hGFC at the concentrations of $0.12 \%$ and $0.2 \%$. AFED was less cytotoxic than CHX. It could be relevant to investigate biopharmaceuticals that do not cause damage to the cells when used for oral hygiene. Since CHX has cytotoxic and inhibitory effects on gingival fibroblasts and on the periodontal ligament, ${ }^{21}$ ED could be proposed as a mouthwash component, since the association of $\mathrm{CHX}$ with AFED resulted in low cytotoxicity to hGFC. It is therefore

$\mathrm{DPPH}$. Radical sequestering activity

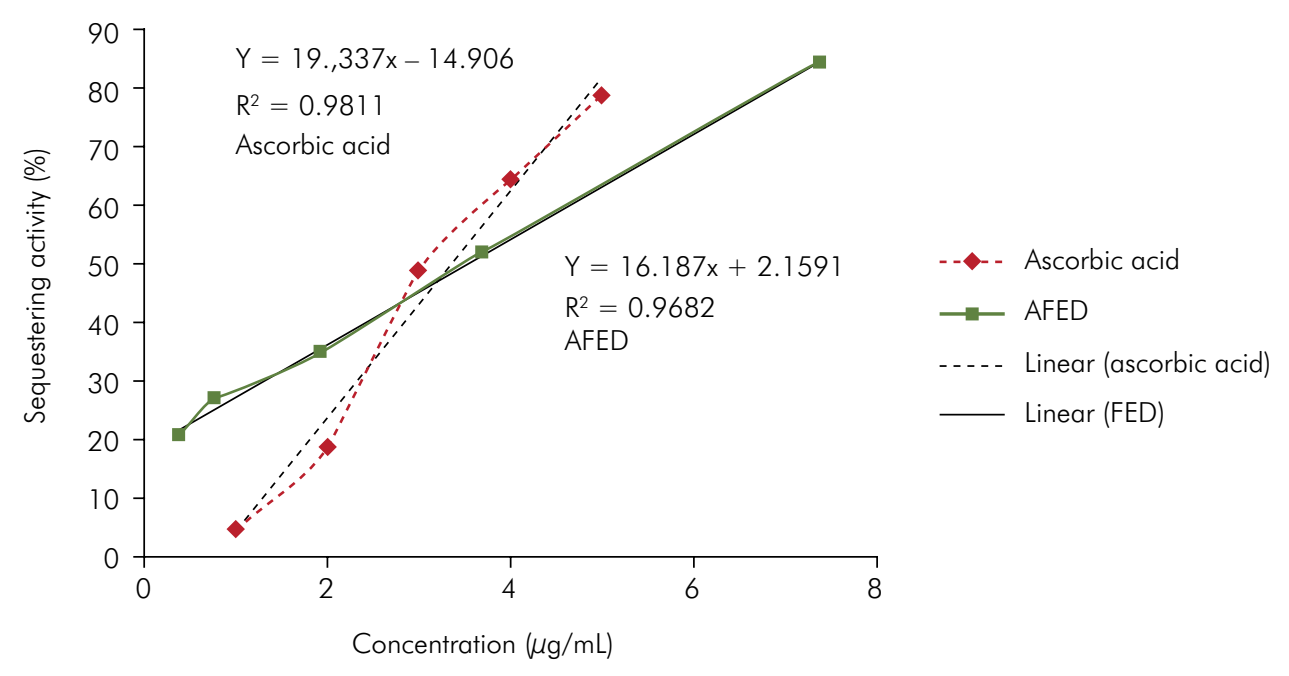

Figure 4. Antioxidant activity by reduction of the DPPH $\bullet$ radical from the acetone fraction of Eugenia dysenterica (AFED) and ascorbic acid standard. Inhibitory concentration 50\% (IC 50) calculated by linear regression in relation to the estimated value of $100 \%$ for the ascorbic acid standard. 

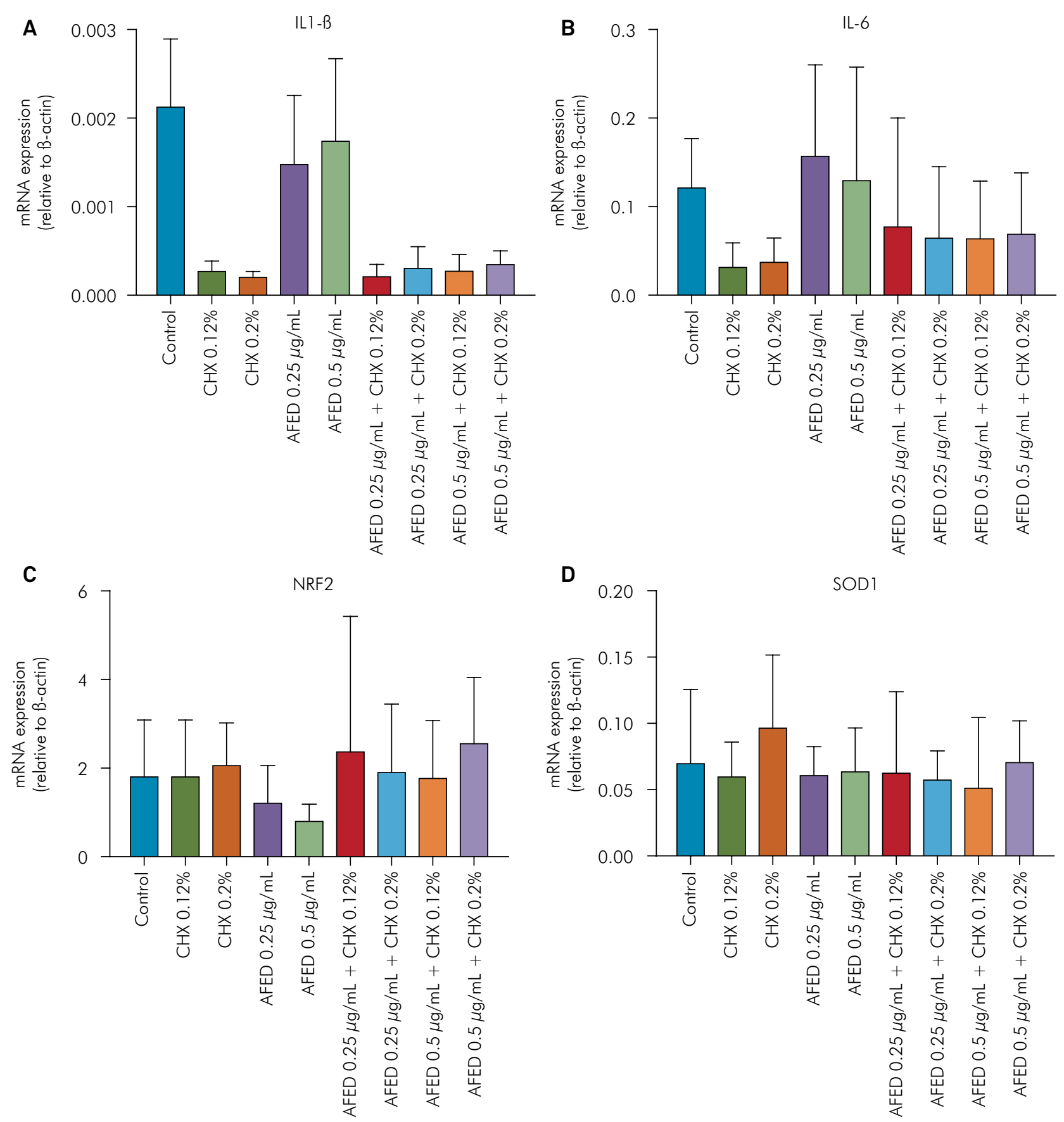

Figure 5. Effect of acetone fraction of Eugenia dysenterica (AFED) in relative mRNA expression in inflammatory and oxidative stress-related genes in gingival fibroblast cells (GFC) after chlorhexidine (CHX) treatment. Cells treated for 24 h and qPCR performed to verify interleukin 1 beta (IL 1 b) (A), interleukin-6 (IL6) (B), nuclear factor erythroid 2-related factor 2 (NRF2) (C), and superoxide dismutase 1 (SOD1) (D) expression. There was no statistical difference between the groups.

suggested that the decrease in cell toxicity is due to the antioxidant effect of the ED extract, as $\mathrm{CHX}$ releases free radicals when decomposed, given its molecular structure and elevated $\mathrm{pH}$ levels. ${ }^{22}$
There is evidence of modulatory effects of phenolic compounds on cells as a result of selective action of different components of signaling cascades, regarded as vital for functions such as growth, proliferation, 
and apoptosis. ${ }^{23}$ The presence of polyphenols was detected in the ED extract, providing it with antioxidant properties. ${ }^{14}$ A recent study has confirmed the presence of catechins in ED with antioxidant effects on skin permeation. ${ }^{24}$ Tannins, flavonoids, terpenes, and saponins were found in the ethanolic extract of ED leaves ${ }^{25}$ providing it with antioxidant properties, which are important for protection against cellular oxidative damage. ${ }^{26}$ In addition, it is widely recognized that flavonoids have antitumor, antiplatelet, anti-allergic, anti-inflammatory, and antibacterial properties, as well as potential for cell differentiation and mineralization, pharmacological activities, and inhibition of lipid oxidation. . $^{10,27}$

In our study, the acetone fraction of the ED extract showed the high efficiency of total phenolic compounds as antioxidants. The antioxidative potential of the extract when combined with the CHX solution was shown by the metabolic activity assay. There was an increase in cell viability when the extract was added, suggesting a cytoprotective effect. The possible sequestration of free radicals released by CHX may have been affected by the presence of tannins in the AFED. ${ }^{28}$ The protective capacity of ED was previously evaluated in an animal study. When tannins were removed, the cytoprotective effect of the extract was lost. ${ }^{15}$

A recent study has shown the antioxidative and cytoprotective effects of the ED extract on murine pulmonary alveolar macrophages exposed to chromium. In addition, higher survival of mice exposed to a lethal dose of chromium was reported. Prophylaxis with the ED extract revealed a reduction in chromium levels in the kidneys, liver, and plasma, as well as prevention of hepatic disorders. ${ }^{29}$

The DPPH• assay is an indirect method for the determination of antioxidant activity and quantification of the antioxidant potential of isolated phenolic compounds. The radical is purple in color by the action of an antioxidant "(AH)" or of a radical species "(R)". DPPH• is reduced and forms diphenyl picrylhydrazine, which has a yellow color because absorption is blocked by antioxidants, and it can be monitored by decreasing absorbance. ${ }^{30}$ Our study suggests antioxidant activity of AFED and interference of SOD1 and NRF2 expression in signaling pathways.
The nitric oxide assay did not demonstrate a positive effect, leading to the conclusion that AFED had no anti-inflammatory activity. Nevertheless, the levels of IL1b mRNA were lower in cells treated with AFED, without statistical significance, probably because of the large standard deviation. The findings of this study may have been biased by the use of primary GFC culture. Despite the lack of statistical significance, the findings may have been influenced by the small number of cell populations.

\section{Conclusion}

The AFED extract had positive effects on hGFC. It is necessary to consider the changes in the cells and the possible antioxidant potential, in addition to the results reported in the literature. Additional studies should be performed with a larger number of cell populations using other concentrations of AFED. Furthermore, the effects of other parts of ED, such as fruits and flowers, on human oral tissues should be evaluated, and the possibility of developing mouthwashes containing AFED should be considered for the treatment of oral disorders.

\section{Acknowledgments}

The authors would like to thank prof. Sueli Maria Gomes (Institute of Biological Sciences of the University of Brasília) for the identification of Eugenia dysenterica. The authors are grateful to the National Council for Scientific and Technological Development (CNPq), Research Incentive Foundation of the Federal District (FAPDF), Coordination for the Improvement of Higher Education Personnel (CAPES), and University of Brasilia (UnB) for funding the present research. Project entitled "Bioprospecting of Cerrado and Pantanal plants for the development of new biopharmaceuticals for the treatment of cancer", edict MCT/CNPq/FNDCT/FAPs/MEC/CAPES/PROCENTRO-OESTE $N^{\circ}$ 031/2010 and Project entitled "Development of new phytotherapics and bioproducts from plant extracts of Eugenia dysenterica, DC and endophitic fungi isolated from this plant, edict MCT/ CNPq/FNDCT/FAPs/MEC/CAPES/PRO-CENTROOESTE N079/2013 MCT/CNPq/FNDCT/FAPs/MEC/ CAPES/PRO-CENTRO-OESTE. 
- In vitro evaluation of Eugenia dysenterica in primary culture of human gingival fibroblast cells

\section{References}

1. Bertolini M, Sobue T, Thompson A, Dongari-Bagtzoglou A. Chemotherapy induces oral mucositis in mice without additional noxious stimuli. Transl Oncol. 2017 Aug;10(4):612-20. https://doi.org/10.1016/j.tranon.2017.05.001

2. Villa A, Sonis ST. Mucositis: pathobiology and management. Curr Opin Oncol. 2015 May;27(3):159-64. https://doi.org/10.1097/CCO.0000000000000180

3. Sonis ST, Villa A. Phase II investigational oral drugs for the treatment of radio/chemotherapy induced oral mucositis. Expert Opin Investig Drugs. 2018 Feb;27(2):147-54. https://doi.org/10.1080/13543784.2018.1427732

4. Wong HM. Oral complications and management strategies for patients undergoing cancer therapy. ScientificWorldJournal. 2014 Jan;2014:581795. https://doi.org/10.1155/2014/581795

5. Carneiro-Neto JN, de-Menezes JD, Moura LB, Massucato EM, de-Andrade CR. Protocols for management of oral complications of chemotherapy and/or radiotherapy for oral cancer: systematic review and meta-analysis current. Med Oral Patol Oral Cir Bucal. 2017 Jan;22(1):e15-23. https://doi.org/10.4317/medoral.21314

6. Cardona A, Balouch A, Abdul MM, Sedghizadeh PP, Enciso R. Efficacy of chlorhexidine for the prevention and treatment of oral mucositis in cancer patients: a systematic review with meta-analyses. J Oral Pathol Med. 2017 Oct;46(9):680-8. https://doi.org/10.1111/jop.12549

7. Jenkins TC, Knepper BC, McCollister BD, Moore SJ, Pawlowski SW, Perlman DM, et al. Failure of outpatient antibiotics among patients hospitalized for acute bacterial skin infections: what is the clinical relevance? Am J Emerg Med. 2016 Jun;34(6):957-62. https://doi.org/10.1016/i.ajem.2016.02.013

8. Cabrera-Jaime S, Martínez C, Ferro-García T, Giner-Boya P, Icart-Isern T, Estrada-Masllorens JM, et al. Efficacy of Plantago major, chlorhexidine $0.12 \%$ and sodium bicarbonate $5 \%$ solution in the treatment of oral mucositis in cancer patients with solid tumour: a feasibility randomised triple-blind phase III clinical trial. Eur J Oncol Nurs. 2018 Feb;32:40-7. https://doi.org/10.1016/j.ejon.2017.11.006

9. Patel M, Ndlovu NN, Owen CP, Veale R. Properties of a new mouthrinse for patients receiving radiation therapy. SADJ. 2010 Oct;65(9):410,412-4.

10. Costa CR, Amorim BR, Magalhães P, Canto GDL, Acevedo AC, Guerra EN. Effects of plants on osteogenic differentiation and mineralization of periodontal ligament cells: a systematic review. Phytother Res. 2016 Apr;30(4):519-31. https://doi.org/10.1002/ptr.5568

11. Freitas MM, Fontes PR, Souza PM, Fagg CW, Guerra ENS, Nóbrega YKM, et al. Extracts of Morus nigra L. leaves standardized in chlorogenic acid, rutin and isoquercitrin: tyrosinase inhibition and cytotoxicity. PLoS One. 2016 Sep;11(9):e0163130. https://doi.org/10.1371/journal.pone.0163130

12. Zorzin FM, Silva SMM, Freitas MM, Coppii RPA, Souza PM, Silveira D, et al. Validation of the analytical method by HPLC for determination of catechin in Eugenia dysenterica DC. dry aqueous extract: a Brazilian savannah native plant. Pharmacologyonline. 2015 Jan;2:100-7.

13. Correia AF, Silveira D, Fonseca-Bazzo YM, Magalhães PO, Fagg CW, Silva EC, et al. Activity of crude extracts from Brazilian cerrado plants against clinically relevant Candida species. BMC Complement Altern Med. 2016 Jul;16(1):203. https://doi.org/10.1186/s12906-016-1164-3

14. Clementino SE, Garcia RS, Moreira BR, Pagliarini BA, Cabral RB, Dâmaris S, et al. Voltammetric and spectrophotometric determination of antioxidant activity of Eugenia dysenterica DC leaves extracts. Pak J Pharm Sci. 2016 Mar;29(2):535-40.

15. Prado LC, Silva DB, Oliveira-Silva GL, Hiraki KR, Canabrava HA, Bispo-da-Silva LB. The gastroprotective effects of Eugenia dysenterica (Myrtaceae) leaf extract: the possible role of condensed tannins. Biol Pharm Bull. 2014;37(5):722-30. https://doi.org/10.1248/bpb.b13-00514

16. Freires IA, Denny C, Benso B, Alencar SM, Rosalen PL. Antibacterial activity of essential oils and their isolated constituents against cariogenic bacteria: a systematic review. Molecules. 2015 Apr;20(4):7329-58. https://doi.org/10.3390/molecules20047329

17. Green LC, Ruiz de Luzuriaga K, Wagner DA, Rand W, Istfan N, Young VR, et al. Nitrate biosynthesis in man. Proc Natl Acad Sci USA. 1981 Dec;78(12):7764-8. https://doi.org/10.1073/pnas.78.12.7764

18. Locatelli M, Gindro R, Travaglia F, Coïsson J, Rinaldi M, Arlorio M. Study of the DPPH • -scavenging activity: development of a free software for the correct interpretation of data. Food Chem. 2009;114(3):889-97. https://doi.org/10.1016/i.foodchem.2008.10.035

19. Huang D, Ou B, Prior RL. The chemistry behind antioxidant capacity assays. J Agric Food Chem. 2005 Mar;53(6):1841-56. https://doi.org/10.1021/if030723c

20. Babich H, Wurzburger BJ, Rubin YL, Sinensky MC, Blau L. An in vitro study on the cytotoxicity of chlorhexidine digluconate to human gingival cells. Cell Biol Toxicol. 1995 Apr;11(2):79-88. https://doi.org/10.1007/BF00767493

21. Flemingson EP, Emmadi P, Ambalavanan N, Ramakrishnan T, Vijayalakshmi R. Effect of three commercial mouth rinses on cultured human gingival fibroblast: an in vitro study. Indian J Dent Res. 2008 Jan-Mar;19(1):29-35. https://doi.org/10.4103/0970-9290.38929 
22. Barbin LE, Estrela C, Guedes DF, Spanó JC, Sousa-Neto MD, Pécora JD. Detection of para-chloroaniline, reactive oxygen species, and 1-chloro-4-nitrobenzene in high concentrations of chlorhexidine and in a mixture of chlorhexidine and calcium hydroxide. J Endod. 2013 May;39(5):664-8. https://doi.org/10.1016/i.joen.2012.10.018

23. Crozier A, Jaganath IB, Clifford MN. Dietary phenolics: chemistry, bioavailability and effects on health. Nat Prod Rep. 2009 Aug;26(8):1001-43. https://doi.org/10.1039/b802662a

24. Ferreira-Nunes R, Angelo T, Silva SM, Magalhães PO, Gratieri T, Cunha-Filho MS, et al. Versatile chromatographic method for catechin determination in development of topical formulations containing natural extracts. Biomed Chromatogr. 2018 Feb;32(2):e4062. https://doi.org/10.1002/bmc.4062

25. Cecílio AB, Faria DB, Oliveira PC, Caldas S, Oliveira DA, Sobral ME, et al. Screening of Brazilian medicinal plants for antiviral activity against rotavirus. J Ethnopharmacol. 2012 Jun;141(3):975-81. https://doi.org/10.1016/i.jep.2012.03.031

26. Sieniawska E. Activities of tannins: from in vitro studies to clinical trials. Nat Prod Commun. 2015 Nov; 10(11):1877-84.

27. Nowwarote N, Osathanon T, Jitjaturunt P, Manopattanasoontorn S, Pavasant P. Asiaticoside induces type I collagen synthesis and osteogenic differentiation in human periodontal ligament cells. Phytother Res. 2013 Mar;27(3):457-62. https://doi.org/10.1002/ptr.4742

28. Rocha WS, Lopes RM, Silva DB, Vieira RF, Silva JP, Agostini-Costa TS. [Total phenolics and condensed tannins in native fruits from Brazilian savanna]. Rev Bras Fruct. 2011;33:1215-21.Portuguese. https://doi.org/10.1590/S0100-29452011000400021

29. Ávila RI, Mattos Alvarenga CB, Ávila PH, Moreira RC, Arruda AF, Fernandes TO, et al. Eugenia dysenterica DC. (Myrtaceae) exerts chemopreventive effects against hexavalent chromium-induced damage in vitro and in vivo. Pharm Biol. 2016 Nov;54(11):2652-63. https://doi.org/10.1080/13880209.2016.1178306

30. Molyneux P. The use of stable free radical diphenylpicrylhydrazyl (DPPH) for estimating antioxidant activity. Songklanakarin J Sci Technol. 2004;26:211-9. 